\title{
Association Between Psychological Distress at Different Points in the Treatment of Esophageal Cancer and Stress-Coping Style
}

Yu Ohkura ( $\nabla$ yu.ohkura107@gmail.com )

Tokyo Medical and Dental University

Kanako Ichikura

Tokyo Medical and Dental University

Junichi Shindoh

Toranomon Hospital

Masaki Ueno

Toranomon Hospital

Harushi Udagawa

Okinaka Memorial Institute for Medical Research

Eisuke Matsushima

Tokyo Medical and Dental University

\section{Research Article}

Keywords: psychological distress, coping, anxiety, depression, esophageal cancer

Posted Date: February 23rd, 2022

DOI: https://doi.org/10.21203/rs.3.rs-1286187/v1

License: (1) This work is licensed under a Creative Commons Attribution 4.0 International License.

Read Full License 


\section{Abstract \\ Background}

Patients with esophageal cancer often have depressed mood and fear of metastasis and death.

Esophagectomy is an invasive procedure with a high incidence of complications. The objective of this study was to examine the association between stress-coping style and psychological distress at different points in the treatment of esophageal cancer.

\section{Methods}

Of 152 consecutive patients treated for esophageal cancer at the outpatient clinic at Toranomon Hospital between April 2017 and April 2019, 102 met the eligibility criteria for this study. Questionnaires designed to identify psychological distress and stress-coping styles were longitudinally administered at 5 time points, from the initial outpatient consultation to 3 months after esophagectomy.

\section{Results}

The coping styles 'fighting spirit' (OR $0.836,95 \% \mathrm{Cl} 0.762-0.918 ; \mathrm{p}<0.001$ ) and 'anxious preoccupation' (OR 1.482, 95\% Cl 1.256-1.748; $p<0.001$ ) were strongly associated with psychological distress before treatment. However, later in treatment, 'helpless/hopeless' (OR 1.337, 95\% Cl 1.099-1.626; $p=0.004$ ) became strongly associated with psychological distress after esophagectomy. There were no relationships between psychological distress and individual patient characteristics, with the exception of 'history of surgery' and 'final staging.' The concordance index was $0.864,0.826,0.839,0.830$, and 0.840 at times $1-5$, respectively.

\section{Conclusions}

The relationship between psychological distress and coping styles was stronger at different points in the treatment of esophageal cancer compared with that between psychological distress and individual patient characteristics. This study used prospective basic clinical data and may provide baseline information for risk stratification in psychological management and for future clinical studies in patients with esophageal cancer.

\section{Background}

Cancer of the esophagus is a highly malignant disease with poor prognosis and is the sixth most common cause of cancer deaths globally [1]. For patients with American Joint Committee on Cancer stage I esophageal cancer, 5-year survival following surgery is approximately $90 \%$; however, this decreases by nearly half for each successive stage (stage II, $45 \%$; stage III, $20 \%$; stage IV, $10 \%$ ) [2-4]. In 
recent years, neoadjuvant chemotherapy and/or radiotherapy has widely been used as an adjunct to surgical resection. The standard treatment for esophageal cancer is esophagectomy, which is a complex and highly invasive gastrointestinal surgery with a high incidence of complications. Although esophagectomy-related mortality and complications have recently been reduced by technical advances in surgery and improvements in perioperative intensive care [5], the procedure still has a reported mortality rate of $2.9-3.0 \%$ and a postoperative complication rate of $42.8-50.0 \%$ [6-8]. The postoperative morbidity rates of pneumonia, prolonged mechanical ventilation, need for transfusion, unplanned intubation, and systemic sepsis are relatively high at $14.6 \%, 10.1 \%, 8.8 \%, 7.2 \%$, and $7.0 \%$, respectively [8]. Previous research on emotional outcomes after resection for esophageal cancer found that a substantial proportion of patients who were alive at 1 year had depressed mood (64\%) and fear of metastasis and death $(80 \%)$ [7]. We previously described the relationship between psychological distress and healthrelated quality of life in esophageal cancer $[9,10]$. It has also been reported that the prevalence of psychological distress varies according to the phase of breast cancer treatment [11]. In lung cancer patients, a greater risk of depression was strongly associated with psychological factors, including personality characteristics (neuroticism) and coping style (low fighting spirit, helplessness/hopelessness, and anxious preoccupation) [12]. In breast cancer patients, coping responses such as fighting spirit and helplessness/hopelessness were significant determinants of psychiatric morbidity [13]. Significant associations have been reported between coping styles and psychological distress [12, 14-16], suggesting that these coping responses may improve the psychological distress that each patient experiences. However, it remains unclear whether this effect is consistent or varies according to the phase of esophageal cancer treatment. Coping styles such as fighting spirit and helplessness/hopelessness have been reported to be important in cancer treatment, but these reports described only one point during treatment for other cancers $[12,13,16]$. Previous reports related to esophageal cancer have also described only one point during treatment [17-19]. Before this study, we hypothesized that certain coping responses would be appropriate at different points in the treatment of esophageal cancer. Few studies have examined risk factors and psychological reactions and conditions at different points in the treatment for esophageal cancer in detail from the initial consultation to 3 months after surgery. Risk factors for psychological distress associated with treatment for esophageal cancer were statistically analyzed. We selected various perioperative variables, including operative findings that are routinely collected at our hospital. We consider that the patient's psychological state might vary during the treatment course. We expected that a deleterious coping response would influence nearly all situations, whereas a beneficial coping response would positively influence situations in which important decisions must be made by the patients. We also expected that patients with a history of surgery might be more resistant to depression compared with patients who had not previously had surgery. If we can describe the relation between perioperative psychological distress and personal coping styles in various situations, it may be possible to develop appropriate supportive interventions to reduce the psychological stress, anxiety, and depressive feelings associated with esophageal cancer. Therefore, the aim of this study was to examine the association between stress-coping style and psychological distress at different points in the treatment of esophageal cancer. 


\section{Methods}

Study Design and Participants

Participants were esophageal cancer patients who visited the outpatient clinic of the Department of Gastrointestinal Surgery at Toranomon Hospital between April 2017 and April 2019. Of 152 consecutive patients who were assessed for eligibility in the trial, 102 met the eligibility criteria and participated in the study, as reported previously $[9,10]$.

The inclusion criteria were a diagnosis of esophageal cancer, including Siewert type I/II esophagogastric junction tumors treated by subtotal esophagectomy, awareness of the cancer diagnosis, performance status $0-2$, age 20-85 years, and ability to provide informed consent. Patients were excluded if informed consent could not be obtained, if they had a history of severe cognitive impairment or a psychiatric disorder, if they were judged by the attending doctor or nurse to be unsuitable for participation in the study because of psychological or physical stress, if they declined surgery, or if they underwent nonsurgical treatment. The flow of patients through the study is shown in Fig. 1.

Questionnaires were administered at 5 time points as follows: at initial consultation at the outpatient clinic or on admission for examination to make a definitive diagnosis (time 1); before treatment after determination of the clinical stage (time 2); at 1 month after esophagectomy before final staging (time 3); at final staging (time 4); and 3 months after esophagectomy (time 5). The questionnaires were administered in the waiting room at our institution (Fig. 1). Disease stage was determined using the UICC TNM grading system, 7th edition [20]. All postoperative complications were graded using the ClavienDindo classification [21]; events more severe than grade III were recorded as complications.

The study protocol was approved by the institutional review boards of the Graduate School of Medical and Dental Sciences (approval number M2016-241) and Toranomon Hospital (approval number 1312) and was registered with the UMIN Clinical Trials Registry (UMIN000029052; 8th / September/ 2017). All procedures were conducted in accordance with the principles of the Helsinki Declaration of 1975 and its later amendments. Informed consent was obtained from all participants at the time of the initial outpatient consultation.

\section{Measures}

Mental Adjustment to Cancer scale

As in our previous related studies [9, 10], we assessed coping styles by using the Mental Adjustment to Cancer (MAC) scale, which is a leading measure of coping and was developed specifically for the assessment of people with cancer. The questionnaire was developed to assess the extent to which patients adopt specific coping strategies as they adjust to the diagnosis and treatment of cancer [12-16]. It was designed to be a patient-friendly self-rated questionnaire that could be easily administered at busy oncology clinics. The scale comprises five subscales measuring different responses: fighting spirit ("I firmly believe that I will get better," 16 items), helpless/hopeless ("I feel that life is hopeless," 6 items), 
anxious preoccupation ("I experience great anxiety about it," 9 items), fatalism ("I've left it all to my doctors," 8 items), and avoidance ("I don't really believe I have cancer," 1 item). Each item is scored on a 4point Likert scale, from 1 ("definitely does not apply to me") to 4 ("definitely applies to me"). Subscale scores are determined by adding up the answers for the assigned items. The reliability and validity of the Japanese version of the MAC scale for Japanese cancer patients were confirmed by Akechi et al. [22]. Generally, coping responses do not change much in the short term; therefore, we did not use the MAC scale at each time point $[23,24]$. In the present study, the questionnaire was administered only once, at time 1.

Hospital Anxiety and Depression Scale

The Hospital Anxiety and Depression Scale (HADS) is a 14-item self-rating tool designed to assess symptoms of anxiety and depression in medical patients, with an emphasis on reducing the impact of physical illness on the total score [25]. HADS comprises two subscales that measure anxiety (HADS-A) and depression (HADS-D). Each subscale contains 7 items, with scores ranging from 0 to 21 [25]. A total score of $\geq 11$ on either subscale indicates a definitive case of psychological distress. We chose this cutoff value on the basis of the Japanese version of HADS, which has been validated for Japanese patients with cancer; a cut-off HADS total score $\geq 11$ has been recommended for identifying patients with potential adjustment disorder and major depression [26, 27]. We defined a total score $\geq 11$ as indicating psychological distress. In the present study, the questionnaire was administered at all 5 time points.

\section{Statistical analysis}

Risk factors for psychological distress related to the treatment of esophageal cancer were assessed by bivariate logistic regression analysis (backward stepwise selection). We selected 31 perioperative variables, including operative findings that are routinely collected at our hospital. As in our previous related studies $[9,10]$, significant differences between the group with HADS scores $\leq 10$ and the group with HADS scores $\geq 11$ were determined using Fisher's exact test, the unpaired Student's t-test, the Mann-Whitney U test, or Pearson's chi-squared test, as appropriate. Variables with a p-value $<0.05$ in the univariate analysis were used in a bivariate logistic analysis. Backward stepwise selection of predictors was used to construct the sets of bivariate logistic analyses in the development cohort, and a p-value less than 0.05 was considered statistically significant in the bivariate logistic analysis. In addition, odds ratios (ORs) and their 95\% confidence intervals (Cls) were calculated. Receiver-operating characteristic (ROC) curve analysis was performed to assess the discrimination ability of the model, that is, the concordance (C)-index (area under the curve) values, at times 1-5. All analyses were performed using SPSS for Windows (version 19.0J; IBM Corp., Armonk, NY).

\section{Results}

Patient characteristics 
In total, 152 consecutive patients were assessed for eligibility, and 50 were excluded for the following reasons: incomplete data $(n=27)$, declined to participate $(n=11)$, did not undergo esophagectomy $(n=$ 11), and receiving treatment for a psychiatric disorder $(n=1)$. This left 102 patients for analysis.

The characteristics of these 102 patients are shown in Table 1. Median age was 68.2 (range 44-86) years, $83.7 \%$ were male, and mean body mass index was $22.3 ; 23.5 \%$ had a history of cancer, $35.3 \%$ had a history of surgery, $86.3 \%$ had a history of alcohol consumption, and $85.3 \%$ had a history of smoking. Total HADS score was $\geq 11$ points in 37 patients (36.3\%) at time $1 ; 41(40.2 \%)$ at time $2 ; 48(47.1 \%)$ at time $3 ; 44(43.1 \%)$ at time 4 ; and $35(34.3 \%)$ at time 5 . The MAC scale scores, which were recorded only at time 1, are shown in Table 1. 
Table 1

Patient demographics and clinical characteristics

\begin{tabular}{|c|c|}
\hline Variables & $\begin{array}{l}\text { Entire study population } \\
(\mathrm{N}=102)\end{array}$ \\
\hline Age, years, median (range) & $68.2(44-86)$ \\
\hline Male sex, \% & 84.3 \\
\hline $\mathrm{BMI}, \mathrm{kg} / \mathrm{m}^{2}$, median & $22.3(14.1-41.9)$ \\
\hline History of cancer & 24 \\
\hline Yes & 78 \\
\hline \multicolumn{2}{|l|}{ No } \\
\hline History of surgery & 36 \\
\hline Yes & 66 \\
\hline \multicolumn{2}{|l|}{ No } \\
\hline History of alcohol consumption & 88 \\
\hline Yes & 14 \\
\hline \multicolumn{2}{|l|}{ No } \\
\hline History of smoking & 87 \\
\hline Yes & 15 \\
\hline \multicolumn{2}{|l|}{ No } \\
\hline Brinkman index & $612(0-3040)$ \\
\hline$<600$ & 44 \\
\hline$\geq 600$ & 58 \\
\hline Thoracic approach & 88 \\
\hline Video-assisted thoracoscopic surgery & 9 \\
\hline Open & 5 \\
\hline None: transhiatal & \\
\hline
\end{tabular}

Abbreviations: BMI, body mass index; EORTC, European Organization for Research and Treatment; HADS, Hospital Anxiety and Depression Scale; HALS, hand-assisted laparoscopic surgery; MAC, Mental Adjustment to Cancer; VATS, video-assisted thoracoscopic surgery 


\begin{tabular}{|c|c|}
\hline Variables & $\begin{array}{l}\text { Entire study population } \\
(\mathrm{N}=102)\end{array}$ \\
\hline Abdominal approach & 47 \\
\hline HALS & 24 \\
\hline Open & 31 \\
\hline \multicolumn{2}{|l|}{ Laparoscopic } \\
\hline Lymphadenectomy & 2 \\
\hline D0 & 2 \\
\hline D1 & 27 \\
\hline D2 & 71 \\
\hline \multicolumn{2}{|l|}{ D3 } \\
\hline Curability & 96 \\
\hline Ro & 6 \\
\hline \multicolumn{2}{|l|}{$\mathrm{R} 1 / 2$} \\
\hline Reconstruction & 66 \\
\hline Gastric tube & 26 \\
\hline Ileocolic & 10 \\
\hline \multicolumn{2}{|l|}{ Other } \\
\hline Thoracic duct & 62 \\
\hline Resected & 40 \\
\hline \multicolumn{2}{|l|}{ Preserved } \\
\hline Reconstruction route & 88 \\
\hline Retrosternal & 14 \\
\hline \multicolumn{2}{|l|}{ Posterior mediastinal } \\
\hline Preoperative treatment & 65 \\
\hline Yes & 37 \\
\hline No & \\
\hline
\end{tabular}

Abbreviations: BMI, body mass index; EORTC, European Organization for Research and Treatment; HADS, Hospital Anxiety and Depression Scale; HALS, hand-assisted laparoscopic surgery; MAC, Mental Adjustment to Cancer; VATS, video-assisted thoracoscopic surgery 


\begin{tabular}{|c|c|}
\hline Variables & $\begin{array}{l}\text { Entire study population } \\
(\mathrm{N}=102)\end{array}$ \\
\hline Operation time (min) & $592(213-774)$ \\
\hline Blood loss (mL) & $205(25-1378)$ \\
\hline G3 postoperative complications & 22 \\
\hline Yes & 80 \\
\hline \multicolumn{2}{|l|}{ No } \\
\hline cT factor (7th ) & $5 / 31$ \\
\hline $1 a / 1 b$ & 25 \\
\hline 2 & 30 \\
\hline 3 & $4 / 7$ \\
\hline \multicolumn{2}{|l|}{$4 a / 4 b$} \\
\hline cN factor (7th ) & 45 \\
\hline 0 & 36 \\
\hline 1 & 19 \\
\hline 2 & 2 \\
\hline \multicolumn{2}{|l|}{3} \\
\hline cStage (7th ) & $27 / 11$ \\
\hline $\mathrm{I}(\mathrm{IA}, \mathrm{IB})$ & $5 / 19$ \\
\hline$\|(I I A, \| B)$ & $13 / 9 / 10$ \\
\hline III (IIIA, IIIB, IIIC) & 8 \\
\hline IV & \\
\hline
\end{tabular}

Abbreviations: BMI, body mass index; EORTC, European Organization for Research and Treatment; HADS, Hospital Anxiety and Depression Scale; HALS, hand-assisted laparoscopic surgery; MAC, Mental Adjustment to Cancer; VATS, video-assisted thoracoscopic surgery 


\begin{tabular}{|c|c|}
\hline Variables & $\begin{array}{l}\text { Entire study population } \\
(\mathrm{N}=102)\end{array}$ \\
\hline p T factor (7th ) & 6 \\
\hline 0 & $9 / 33$ \\
\hline $1 a / 1 b$ & 20 \\
\hline 2 & 27 \\
\hline 3 & $5 / 2$ \\
\hline \multicolumn{2}{|l|}{$4 a / 4 b$} \\
\hline p N factor (7th ) & 49 \\
\hline 0 & 28 \\
\hline 1 & 15 \\
\hline 2 & 10 \\
\hline \multicolumn{2}{|l|}{3} \\
\hline p Stage (7th ) & 3 \\
\hline 0 & $32 / 5$ \\
\hline $\mathrm{I}(\mathrm{IA}, \mathrm{IB})$ & $3 / 16$ \\
\hline II (IIA, IIB) & $19 / 8 / 11$ \\
\hline III (IIIA, IIIB, IIIC) & 5 \\
\hline \multicolumn{2}{|l|}{ IV } \\
\hline Location of tumor & 4 \\
\hline Cervical Esophagus & 19 \\
\hline Upper thoracic esophagus & 46 \\
\hline Middle thoracic esophagus & 20 \\
\hline Lower thoracic esophagus & 1 \\
\hline Abdominal esophagus & 12 \\
\hline \multicolumn{2}{|l|}{ Esophagogastric junction } \\
\hline \multicolumn{2}{|l|}{ MAC scale } \\
\hline Fighting spirit & $47.8(27-60)$ \\
\hline $\begin{array}{l}\text { Abbreviations: BMI, body ma } \\
\text { HADS, Hospital Anxiety and } \\
\text { Mental Adjustment to Cance }\end{array}$ & $\begin{array}{l}\text { zation for Research and Treatment; } \\
\text { isted laparoscopic surgery; MAC, } \\
\text { pic surgery }\end{array}$ \\
\hline
\end{tabular}




\begin{tabular}{|c|c|}
\hline Variables & $\begin{array}{l}\text { Entire study population } \\
(\mathrm{N}=102)\end{array}$ \\
\hline Helpless/ Hopeless & $9.2(6-24)$ \\
\hline Anxious Preoccupation & $22.6(13-32)$ \\
\hline Fatalism & $20.2(8-30)$ \\
\hline Avoidance & $1.6(1-4)$ \\
\hline HADS, time 1 & 65 \\
\hline $\begin{array}{l}\leq 10 \\
\geq 11\end{array}$ & $37(36.2 \%)$ \\
\hline $\begin{array}{l}\text { HADS, time } 2 \\
\leq 10 \\
\geq 11\end{array}$ & $\begin{array}{l}61 \\
41(40.2 \%)\end{array}$ \\
\hline $\begin{array}{l}\text { HADS, time } 3 \\
\leq 10 \\
\geq 11\end{array}$ & $\begin{array}{l}54 \\
48(47.1 \%)\end{array}$ \\
\hline $\begin{array}{l}\text { HADS, time } 4 \\
\leq 10 \\
\geq 11\end{array}$ & $\begin{array}{l}58 \\
44(43.1 \%)\end{array}$ \\
\hline $\begin{array}{l}\text { HADS, time } 5 \\
\leq 10 \\
\geq 11\end{array}$ & $\begin{array}{l}67 \\
35(34.3 \%)\end{array}$ \\
\hline $\begin{array}{l}\text { Abbreviations: BMI, bod } \\
\text { HADS, Hospital Anxiety } \\
\text { Mental Adjustment to C }\end{array}$ & $\begin{array}{l}\text { Ization for Research and Treatment; } \\
\text { isted laparoscopic surgery; MAC, } \\
\text { pic surgery }\end{array}$ \\
\hline
\end{tabular}

Independent risk factors for psychological distress in bivariate analysis

We used the variables for each of the 5 times in the analysis. As in our previous studies $[9,10], 31$ variables were used for the univariate analysis (Supplemental Table 1). Variables with a p-value $<0.05$ in the univariate analysis were used in the bivariate logistic analysis.

The independent risk factors for psychological distress at times 1-5 are shown in Table 2. Independent predictors of psychological distress at time 1 were fighting spirit (OR $0.836,95 \% \mathrm{Cl} 0.762-0.918 ; \mathrm{p}<$ 0.001 ) and anxious preoccupation (OR 1.482, 95\% Cl 1.256-1.748; $p<0.001)$. Independent predictors at 
time 2 were fighting spirit (OR $0.885,95 \% \mathrm{Cl} 0.803-0.977 ; \mathrm{p}=0.015)$ and helpless/hopeless (OR 1.337, $95 \% \mathrm{Cl} 1.099-1.626 ; p=0.004)$. At times $3-5$, independent predictors were helpless/hopeless. At time 4, final disease staging after esophagectomy $(\mathrm{OR} 2.379,95 \% \mathrm{Cl} 1.430-3.957 ; \mathrm{p}=0.001)$ and fighting spirit (OR $0.913,95 \% \mathrm{Cl} 0.847-0.983 ; \mathrm{p}=0.016$ ) were identified as independent risk factors.

Table 2

Risk factors for psychological distress at Time 1 to Time 5

\begin{tabular}{|llll|}
\hline Variables & Odds ratio & $95 \%$ Cls & p-value \\
\hline Time 1 & & & \\
\hline MAC; Fighting spirits & 0.836 & $0.762-0.918$ & $<0.001$ \\
\hline ;Anxious preoccupation & 1.482 & $1.256-1.748$ & $<0.001$ \\
\hline Time 2 & & & \\
\hline MAC; Fighting spirits & 0.911 & $0.837-0.991$ & 0.029 \\
\hline ; Helpless/ Hopeless & 1.337 & $1.099-1.626$ & 0.004 \\
\hline Time 3 & & & \\
\hline MAC; Helpless/ Hopeless & 1.599 & $1.313-1.948$ & $<0.001$ \\
\hline History of surgery & 3.496 & $1.272-9.604$ & 0.015 \\
\hline Time 4 & & & \\
\hline p-Stage (7th ) & 2.379 & $1.430-3.957$ & 0.001 \\
\hline MAC; Fighting spirits & 0.913 & $0.847-0.983$ & 0.016 \\
\hline ; Helpless/ Hopeless & 1.309 & $1.112-1.541$ & 0.001 \\
\hline Time 5 & & & \\
\hline MAC; Helpless/ Hopeless & 1.575 & $1.303-1.905$ & $<0.001$ \\
\hline Abbreviations: MAC, Mental Adjustment to Cancer; Cls, Confidence interval \\
\hline
\end{tabular}

Performance of the analyses

The C-index values for these bivariate analyses at times 1-5 are summarized in Table 3 . The areas under the ROC curve were $0.864,0.826,0.839,0.830$, and 0.840 at times $1-5$, respectively. The internal consistency (reliability) of each scale was estimated using Cronbach's alpha, and a value of 0.70 or greater was considered acceptable for group comparisons [28]. In this study, the Cronbach's alpha coefficient between the MAC scale and some variables of the HADS scale at several points of perioperative treatment were as follows: time 1 , fighting spirit $(a=0.750)$, anxious preoccupation $(a=$ $0.602)$; time 2 , fighting spirit $(a=0.702)$, helpless/hopeless $(a=0.673)$; time 3 , helpless/hopeless $(a=$ 
$0.592)$; time 4 , fighting spirit $(a=0.838)$, helpless/hopeless $(a=0.630)$; time 5 , helpless $/$ hopeless $(a=$ $0.662)$.

Table 3

Evaluation of the predictive ability of the risk model at times $1-5(\mathrm{~N}=102)$

\begin{tabular}{|llll|}
\hline Complications & $\mathbf{C}$ index & $\mathbf{9 5 \%} \mathrm{Cl}$ & p-value \\
\hline Time 1 & 0.864 & $0.792-0.936$ & $<0.001$ \\
\hline Time 2 & 0.826 & $0.741-0.911$ & $<0.001$ \\
\hline Time 3 & 0.839 & $0.757-0.920$ & $<0.001$ \\
\hline Time 4 & 0.830 & $0.749-0.911$ & $<0.001$ \\
\hline Time 5 & 0.840 & $0.759-0.920$ & $<0.001$ \\
\hline C index, concordance index; Cl, confidence interval \\
\hline
\end{tabular}

\section{Discussion}

In this study, we evaluated the association between stress-coping style and psychological distress at different points in the treatment for esophageal cancer. The time points ranged from the first outpatient consultation (time 1) to 3 months after esophagectomy (time 5). Our results showed that the relationship between psychological distress and psychological factors such as coping style, was stronger than that between psychological distress and individual patient characteristics. The C-index for these analyses showed high predictive performance at all five times. This study is the first to use prospective clinical data to analyze the relationship between psychological distress and coping style at different points in the treatment of esophageal cancer and may serve as a baseline for future research.

In a previous study, Hellstadius et al. [29] reported that the proportion of patients with anxiety was $33 \%$ prior to surgery, $28 \%$ at 6 months, and $37 \%$ at 12 months, while the proportion with depression was $20 \%$ prior to surgery, $27 \%$ at 6 months, and $32 \%$ at 12 months. They concluded that symptoms of anxiety remained stable over time, whereas those of depression appeared to increase from pre-surgery to 6 months, leveling off between 6 and 12 months. In addition, the proportion of patients with psychological distress was $36.2 \%$ at the initial consultation, $40.2 \%$ prior to surgery, $47.1 \%$ at 14 days after surgery, $43.1 \%$ at 1 month, and $34.3 \%$ at 3 months (Table 1 ). In our study, the results differed slightly in that psychological distress appeared to increase from the initial outpatient consultation to about 14 days after surgery, gradually decreasing from 1 month to 3 months after surgery. This study is also the first to examine in detail the risk factors and psychological reactions or conditions at different points in treatment from the initial consultation to 3 months after surgery.

Significant associations have been reported between coping styles and psychological distress [14-16], suggesting that coping responses may improve the psychological distress that each patient experiences. 
In addition, the way in which patients cope with and adjust to threats is reported to be associated with depression [12]. However, it remains unclear whether this effect is consistent or varies according to the phase of esophageal cancer treatment. Therefore, we investigated in more detail the association between stress coping style and psychological distress at different points in the treatment of esophageal cancer.

Patients with a helpless/hopeless response and anxious preoccupation were at increased risk of psychological distress during the course of treatment for esophageal cancer, whereas those with a fighting spirit response were better able to adjust to their situation $[14,15]$. Previous studies of the association between psychological distress and coping style have suggested that the most beneficial response is fighting spirit and the most deleterious response may be helpless/hopeless $[13,16,26]$. However, a systematic review by Petticrew et al. [30] could not confirm an association between fighting spirit and psychological distress. Other studies have reported that esophageal cancer patients who maintain a positive focus appear to experience less psychological distress [18, 31, 32]. However, these studies did not consider the various points of treatment. Therefore, it is unclear whether the benefits of staying positive can be observed throughout the treatment course or only during some limited phases. In the present study, helpless/hopeless response increased the risk of psychological distress at nearly all points (times 2-5). Anxious preoccupation was a risk factor only at time 1. Meanwhile, patients with a fighting spirit had fewer symptoms of anxiety and depression at diagnosis in the outpatient clinic (time 1), at the determination of the clinical stage (time 2), and at the determination of final staging (time 4). Although esophagectomy-related mortality and complications have recently been reduced by technical advances in surgery and improvements in perioperative intensive care [5], the procedure still has a reported mortality rate of $2.9-3.0 \%$ and a postoperative complication rate of $42.8-50.0 \%[2,6,8]$. These esophageal cancer patients had depressed mood and expressed fear of metastases and death during the course of treatment. In the present study, we found that deleterious coping styles such as helpless/hopeless and anxious preoccupation affected the psychological response at all points examined during the treatment course, whereas beneficial coping styles such as a fighting spirit affected the psychological response at important points, including the initial outpatient consultation, determination of the clinical stage, and determination of the final stage after esophagectomy. Although a fighting spirit and anxious preoccupation were strongly associated with psychological distress before treatment, as the treatment course progress helpless/hopeless became strongly associated with psychological distress after esophagectomy. Therefore, we should not pressure patients to have a fighting spirit after esophagectomy, and it is important not to let patients have feelings of helplessness and hopelessness. It is therefore important to provide continuous support so that patients do not lose hope as they battle esophageal cancer. The two other coping styles, fatalism and avoidance, were not found to be significant risk factors for psychological distress in this study.

A previous study reported an association between tumor stage and psychological distress [33], which is thought to be due to the patient's regret at allowing the cancer to progress to an advanced stage. The results of the present study also suggest that pathological stage may be a significant risk factor for psychological distress when final staging is determined after esophagectomy (time 4). According to an earlier study on emotional outcomes after resection for esophageal cancer, around $80 \%$ of patients who 
were alive at 1 year reported being afraid of metastasis and death [7]. For this reason, it is our recommendation that a method of supportive care be developed to reduce anxiety and promote coping strategies in patients with esophageal cancer that has progressed to an advanced stage.

Before this study, we expected that patients with a history of surgery might be less prone to depressed mood compared with patients who had not previously had surgery. However, we found that a history of surgery was a significant risk factor for psychological distress, but only at 1 month postoperatively before final staging (time 3 ). One possible explanation for this is that these patients may have felt postoperative distress that was substantially different from the previous operations because esophagectomy is one of the most invasive types of gastrointestinal surgery. Another explanation might be that the esophagectomy in patients with a history of abdominal or thoracic surgery tends to be more complex and time-consuming, leading to greater postoperative pain and discomfort.

At our hospital, we have a system in place through which various kinds of medical professionals, including gastroenterologists, surgeons, nurses, nutritionists, dentists, otolaryngologists, and physical therapists, support esophageal cancer patients. However, to date, no psychiatrists or clinical psychologists have participated in this system. It would thus be beneficial to have psychiatrists offer mental health interventions to patients who show the predictive factors of psychological distress before the start of treatment. For this reason, we have deemed it necessary to add psychiatrists and clinical psychologists as members of the esophageal cancer support team at our hospital. It is our hope that other hospitals in Japan will also organize such teams in order to provide more detailed and personalized mental interventions going forward.

This study has some limitations, the largest of which are its small sample size, its single-center design, and its focus on a Japanese population. Therefore, our observations should be confirmed by an external validation study or an international multicenter trial with a larger number of cases. In addition there were several factors that we could not control for that may be associated with psychological distress related to treatment for esophageal cancer. Despite this, our results indicated that the risk of psychological distress could be estimated reasonably accurately from the clinical factors we investigated in this study. Thus, the results of this analysis may be helpful for stratifying risk stratification in the clinical setting. Based on this, it is important information to prospectively collect clinical data with an eye toward improving the psychological management of patients undergoing treatment for esophageal cancer.

\section{Conclusion}

This study showed that the relationship between psychological distress and coping styles was stronger at different points in the treatment of esophageal cancer than that between psychological distress and individual patient characteristics. This study used basic clinical data and may provide baseline information for risk stratification toward psychological management and for future clinical studies in these patients. 


\section{Abbreviations}

MAC scale, Mental Adjustment to Cancer scale; HADS, Hospital Anxiety and Depression Scale; ORs, odds ratios; $95 \% \mathrm{Cls}$, 95\% confidence intervals; ROC curve, receiver-operating characteristic curve

\section{Declarations}

Ethics approval and consent to participate:

The study protocol was approved by the institutional review boards of the Graduate School of Medical and Dental Sciences (approval number M2016-241) and Toranomon Hospital (approval number 1312) and was registered with the UMIN Clinical Trials Registry (R000033229). Written informed consent was obtained from all of the patients for the publication of this report.

Consent to publish:

Not applicable

Availability of data and materials:

The datasets generated and analyzed during the current study are not publicly available given the restrictions to data sharing imposed, but de-identified data are available from the corresponding author on reasonable request.

Funding:

None

Competing interests:

We have no conflict of interest to declare

Authors' Contributions:

Yu Ohkura, Kanako Ichikura, and Eisuke Matsushima designed the study, wrote the manuscript, revised it critically for important intellectual content, and approved its content; Yu Ohkura, Kanako Ichikura, Junichi Shindoh, Masaki Ueno, Harushi Udagawa, and Eisuke Matsushima created the study materials and recruited the participants.

Acknowledgments:

None

\section{References}


1. Jemal A, Bray F, Center M, et al. Global cancer statics. CA Cancer J Clin. 2011;61:69-90.

2. Takeuchi H, Miyata H, Gotoh M, Kitagawa Y, Baba H, Kimura W, et al. A risk model for esophagectomy using data of 5354 patients included in a Japanese nationwide web-based database. Ann surg. 2014; 260: 259-266.

3. Daly JM, Fry WA, Little AG, et al. Esophageal cancer: Results of an American College of Surgeons Patient Care Evaluation Study. J Am Coll Surg 2000;190:562-572.

4. Suntharalingam M, Moughan J, Coia LR, et al. Outcome results of the 1996-1999 patterns of care survey of the national practice for patients receiving radiation therapy for carcinoma of the esophagus. J Clin Oncol 2005;23:2325-2331.

5. Takeuchi H, Saikawa Y, Oyama T, Ozawa S, Suda K, Wada N, et al. Factors influencing the long-term survival in patients with esophageal cancer who underwent esophagectomy after chemoradiotherapy. World J Surg. 2010;34:277-284.

6. Birat D, Brian SD, John GH, Brett CS, John TV, James PD. Patient and peri-operative predictors of morbidity and mortality after esophagectomy: American College of Surgeons National Surgical Quality Improvement Program (ACS-NSQIP), 2005-2008. J Gastrointest Surg. 2010; 14: 1492-1501.

7. Hellstadius Y, Lagergren P, Lagergren J, et al. Aspects of emotional functioning following oesophageal cancer surgery in a population-based cohort study. Psycho-Oncology. 2015; 24: 47-53.

8. Ohkura Y, Miyata $\mathrm{H}$, Konno $\mathrm{H}$, et al. Development of a model predicting the risk of eight major postoperative complications after esophagectomy based on 10826 cases in the Japan National Clinical Database. J Surg Oncol. 2020; 121: 313-321.

9. Ohkura Y, Ichikura K, Shindoh J, et al. Relationship between psychological distress and health-related quality of life at each point of the treatment of esophageal cancer. Esophagus. 2020; 17: 312-322.

10. Ohkura Y, Shindoh J, Ichikura K, et al. Perioperative risk factors of psychological distress in patients undergoing treatment for esophageal cancer. World J surg Oncol. 2020; 18: 326-338.

11. Iwatani T, Matsuda A, Kawabata $\mathrm{H}$, et al. Predictive factors for psychological distress related to diagnosis of breast cancer. Psycho-Oncology. 2013; 22: 523-529.

12. Shimizu K, Nakaya N, Saito-Nakaya K, et al. Clinical biopsychosocial risk factors for depression in lung cancer patients: a comprehensive analysis using data from the Lung Cancer Database Project. Annals on Oncology. 2012; 23: 1973-1979.

13. Akechi T, Okuyama T, Imoto S, et al. Biomedical and psychological determinants of psychiatric morbidity among postoperative ambulatory breast cancer patients. Breast Cancer Research and Treatment. 2001; 65: 195-202.

14. Osborne RH, Elsworth GR, Kissane DW, et al. The Mental Adjustment to Cancer (MAC) Scale: replication and refinement in 632 breast cancer patients. Psychological Medicine. 1999; 29: 13351345.

15. Watson M, Greer S, Young J, et al. Development of a questionnaire measure of adjustment to cancer: the MAC scale. Psychological Medicine. 1988; 18: 203-209. 
16. Akechi T, Kugaya A, Okamura $\mathrm{H}$, et al. Predictive factors for psychological distress in ambulatory lung cancer patients. Support Care Cancer. 1998; 6: 281-286.

17. Cotton RG, Langer R, Leong T, et al. Coping with esophageal cancer approaches worldwide.Ann $N$ Y Acad Sci. $2014 ; 1325: 138-58$.

18. Han Y, Hu D, Liu Y, et al. Coping styles and social support among depressed Chinese family caregivers of patients with esophageal cancer. European $\mathrm{J}$ of Oncol Nursing. 2014; 18: 571-577.

19. KilbaneKS, Girgla N, Zhao L, et al.Adaptive andMaladaptive Coping Mechanisms Used by Patients With Esophageal Cancer After Esophagectomy.J Surg Res. 2021; 258:1-7.

20. Sobin LH, Gospodarowicz MK, Wittekind C, editors. International Union Against Cancer. Oesophagus including oesophagogastric junction. "TNM classification of malignant tumours". West Sussex,UK: Wiley-Blackwell; 2009: 66-72.

21. Dindo D, Demartines N, Clavien PA. Classification of surgical complications: a new proposal with evaluation in a cohort of 6336 patients and results of a survey. Ann Surg 2004; 240: 205-213.

22. Akechi T, Fukue-Saeki M, Kugaya A, et al. Psychometric properties of the Japanese version of the MentalAdjustmentto Cancer (MAC) scale. 2000; 9: 395-401.

23. Aldwin CM, Revenson TA.Does coping help? A reexamination of the relation between coping and mental health. Journal of Personality and Social 1987; 53: 337-348.

24. Sandler IN, Tein JY, Mehta P, et al. Coping efficacy and psychological problems children of divorce. Child Development. 2000; 71: 1099-1118.

25. Zigmond AS, Snaith RP. The hospital anxiety and depression scale. Acta Psychiatr Scand. 1983; 67: 361-370.

26. Kugaya A, Akechi T, Okuyama T et al. Screening for psychological distress in Japanese cancer patients. Jpn J Clin Oncol 1998;28(5):333-338

27. Kitamura T. Hospital Anxiety and Depression Scale. Seisinka Sindangaku 1993; 4: 371 372(Japanese).

28. Cronbach LJ. CoeYcient alpha and the internal structure of tests. Psychometrika 1951, 16, 297.

29. Hellstadius $Y$, Lagergren J, Zylstra J et al. A longitudinal assessment of psychological distress after oesophageal cancer surgery. ACTA Oncology. 2017; 56: 746-752.

30. Petticrew $M$, Bell $R$, and Hunter $D$. Influence of psychological coping on survival and recurrence in people with cancer: systemic review. BMJ. 2002; 325: 1066.

31. Martin D, Noleen K,Mc Corry, Emma B, et al. Psychological distress among family carers of oesophageal cancer survivors: the role of illness cognitions and coping. Psycho-Oncology. 2011; 20: 698-705.

32. Martin D, Noleen K,Mc Corry, Emma B, et al. Psychological distress among survivors of esophageal cancer: the role of illness cognitions and coping. Diseases of the Esophagus. 2012; 25: 222-227.

33. Gilbar $\mathrm{O}$, Hevroni A. Counterfactual, coping strategies and psychological distress among breast cancer patients. Anxiety Stress Coping. 2007; 20: 383-392. 
Figures

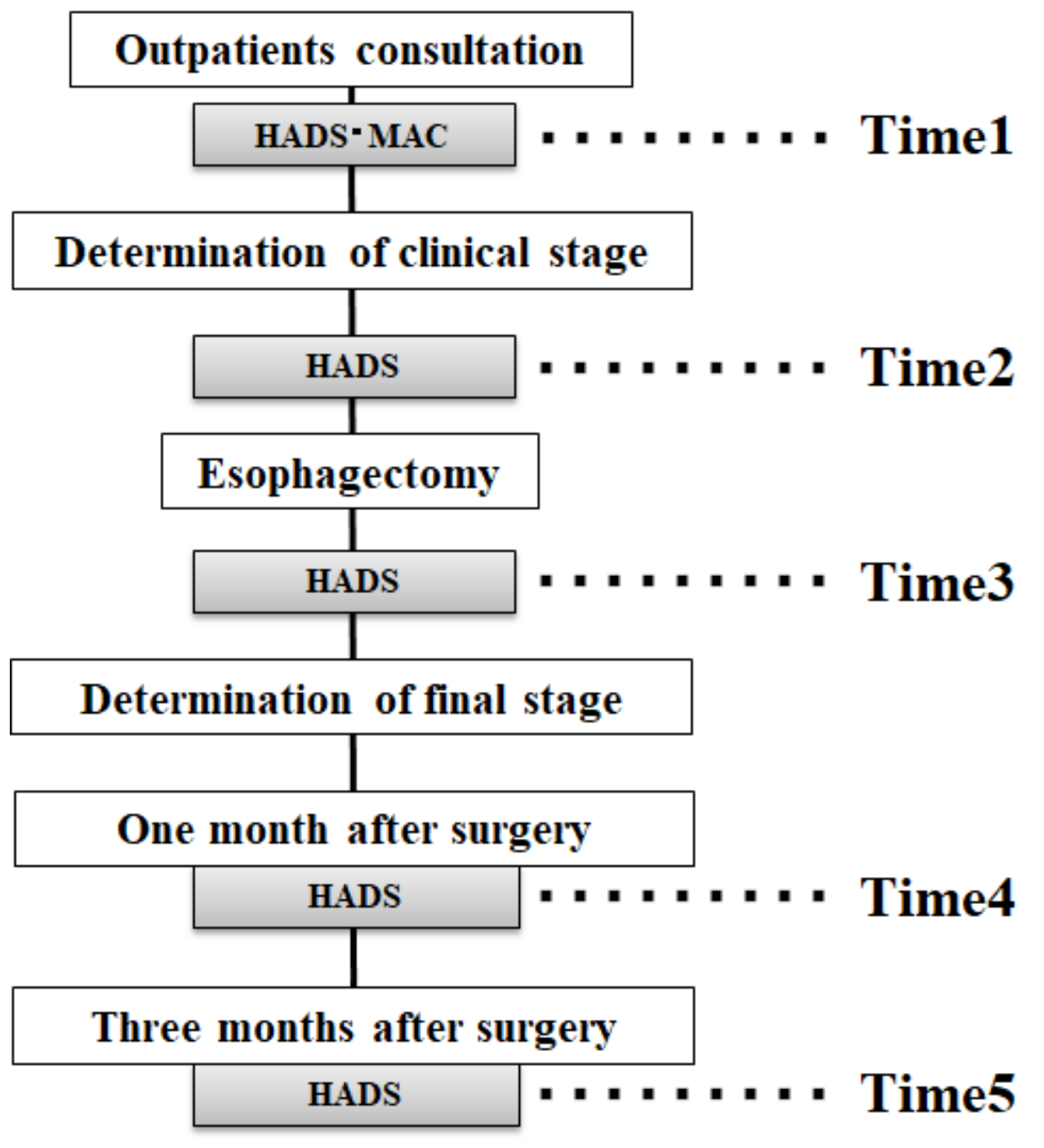

Figure 1

Flow of patients through the study

Time 1, before definitive diagnosis; time 2, after determination of the clinical stage; time 3 , postoperatively before final staging; time 4 , determination of the final stage at 1 month after esophagectomy; time 5, 3 months after esophagectomy.

\section{Supplementary Files}

This is a list of supplementary files associated with this preprint. Click to download.

- REVISESupfigure.pdf

- SupMACscale1.docx 
- Supplementaltable11.docx

- Supplementaltable21.docx

- Supplementaltable31.docx

- Supplementaltable41.docx

- Supplementaltable51.docx

- SupHADS1.docx 